\title{
A Special Issue on Microorganisms from Extreme Environments in Memory of Luigi Michaud (1974-2014)
}

\author{
Angelina Lo Giudice ${ }^{1, *(D)}$ and Concetta Gugliandolo ${ }^{2}$ (D) \\ 1 Institute of Polar Sciences, National Research Council (CNR-ISP), Spianata San Raineri 86, \\ 98122 Messina, Italy \\ 2 Department of Chemical, Biological, Pharmaceutical and Environmental Sciences (ChiBioFarAm), \\ University of Messina, Viale F. Stagno d'Alcontrès 31, 98168 Messina, Italy; cgugliandolo@unime.it \\ * Correspondence: angelina.logiudice@cnr.it; Tel.: +39-090-601-5415
}

Received: 29 November 2019; Accepted: 3 December 2019; Published: 18 December 2019

\begin{abstract}
A special issue (SI) titled "Microbial Diversity in Extreme Environments: Implications for Ecological and Applicative Perspectives" has been launched with the aim of showcasing the diversity and biotechnological potential of extremophilic microorganisms. The issue includes 10 research papers and four reviews that mainly address prokaryotes inhabiting hyperarid, hypercold, hyperalkaline and hypersaline (or polyextreme) environments, spanning from deserts to meromictic and glacier lakes around the globe. Thermophilic prokaryotes from shallow hydrothermal vents and Antarctic geothermal soils are also treated. The ecology and biotechnological perspectives of eukaryotes are discussed in two review papers and one research paper. This special issue serves as a memorial to Dr. Luigi Michaud (1974-2014), who dramatically passed away in Antarctica during underwater sampling activities.
\end{abstract}

Keywords: extremophiles; biotechnological potentialities; microbial life in extreme environments

Low or high temperatures, high ionic strength and/or pressure, absence of sunlight, low water content, low or high $\mathrm{pH}$ values, and high levels of radiation are only some examples of physical and chemical conditions characterizing extreme environments that are intolerably hostile (or even lethal) to most known life forms. However, one has to keep in mind that the definition of "extreme conditions" derives from an anthropocentric point of view, rather than from microbial criteria [1]. Unexpected high levels of microbial diversity and microbial community complexity have been revealed by the application of modern advanced techniques in molecular biology. Extremophilic microorganisms include members of all three domains of life (i.e., Bacteria, Archaea, and Eukarya). They can be classified in psychrophiles and thermophiles, halophiles, acidophiles, alkalophiles, and piezophiles, according to the conditions in which they grow (polyextremophiles also exist). Extremophiles offer a variety of adaptation strategies involving structural, physiological, and metabolic modifications that make them of interest in pure and applied research.

This special issue (SI) comprises 10 research papers and four review papers, some of which address specific perspectives of extremophilic lifestyles in relation to (poly)extreme environmental conditions. Interestingly, Saenz et al. [2] explore the role played by mobile genetic elements (MGEs) in the adaptation of the microbiome in soils of the Atacama Desert along a precipitation gradient, decreasing from the arid coast to the hyperarid inland region of the desert. Results reveal that housekeeping genes involved in energy production could be modulated in hyperarid sites, suggesting an adaptive advantage to the bacterial community under hyperarid conditions. 
Two papers deal with the microbial community in Antarctic lakes and/or ponds, exploring the biodiversity of microorganisms within all of the three domains of life (Bacteria, Archaea and Eukarya) [3,4]. In the Lake Yukidori-Ike, a glacier lake in East Antarctica, Chaya et al. [3] report a remarkably higher diversity of Bacteria (mainly Betaproteobacteria) and Eukarya (e.g., Tardigrada, Ciliophora, Cryptomycota, Chlorophyta, Bacillariophyta, and Apusozoa) than those of Archaea, which were exclusively represented by the methanogenic Euryarchaea Methanosarcina sp. and Methanosaeta sp. The similarities in species compositions of Lake Yukidori-Ike with temperate freshwater environments rather than Antarctic saline lakes indicate that salinity affects the structure of whole microbial communities more than temperature. Rochera and Camacho [4] comprehensively review the microbial ecology of lakes and ponds in Byers Peninsula (Livingston Island, South Shetland Islands, Antarctica), highlighting the strong influence of physical and chemical factors (e.g., temperature, availability of light, and nutrients), and also explore the role of top-down biotic processes, in shaping the microbial communities (including viruses, bacteria, and protists). With respect to lakes in temperate regions, the prokaryotic community (Bacteria and Archaea) of the peculiar meromictic Lake Faro in the North-Eastern corner of Sicily (Italy) undergoes a seasonal and spatial (along the water column) variability that is strongly dependent on changes in environmental variables (e.g., temperature, dissolved oxygen, redox potential, salinity) and mixing conditions [5].

The sole bacterial community is the subject of four SI papers exploring environments with peculiar features, such as volcanic gas-affected soils [6], $\mathrm{CO}_{2}$ leakage sites [7], epilithon [8], and hyperalkaline steel slag waterways [9]. Fagorzi et al. [6] investigate the possible correlation between interstitial soil gases and soil bacteria in two sites at Vulcano Island (Eolian Islands, Italy): La Fossa Crater (affected by an intense fumarolic degassing, with outlet temperatures up to $450{ }^{\circ} \mathrm{C}$ ) and the Levante Bay (characterized by the presence of low-temperature fumaroles, $<100^{\circ} \mathrm{C}$, both subaerial and submerged). The similarities observed between sites showing different emission profiles suggest that the bacterial communities could share metabolic activities related to gas composition. Ma et al. [7] use network analyses to explore interactions between soil bacterial taxa at $\mathrm{CO}_{2}$ leakage points at $\mathrm{CO}_{2}$-EOR $\left(\mathrm{CO}_{2}\right.$-enhanced oil recovery) sites, using $\mathrm{CO}_{2}$ to enhance oil recovery or improve the recovery ratio of oil reservoirs. Main findings demonstrate that both microbial interactions and dominant phyla vary across $\mathrm{CO}_{2}$ concentrations, with network interactions for most of the microbial groups that become less complex under higher $\mathrm{CO}_{2}$ concentration. According to Chiellini et al. [8], the bacterial community in the red epilithon (epilithic biofilm) covering the rocks (enriched with heavy metals due to past metallurgic activities) surrounding the Infernaccio Waterfalls (Italy) shares similar features with black epilithic biofilm of the Acquarossa River. However, the red epilithon of Infernaccio was dominated by Acinetobacter members, with few representatives of Arthrobacter sp., Solibacillus sp., Serratia sp., Rhizobium sp., Paracoccus sp., and Yersinia sp. (not detected in the Acquarossa red epilithon). The different chemico-physical composition of Infernaccio and Acquarossa red epilithons probably plays a key role in structuring the bacterial communities at genus level. Finally, Ohlsson et al. [9] report on the microbial colonization of an extremely alkaline and heavily polluted (including heavy metals) environment, the Calumet Wetlands (Chicago, USA), as well as on the potential use on microbes inhabiting such extreme environments in the remediation of Calumet and similarly contaminated sites. Serpentinomonas relatives were among a few species thriving with extremely alkaline $\mathrm{pH}$. Understanding their survival mechanisms could also help the comprehension of microbial life in serpentinization-like conditions on Earth and other planets.

The archaeal community is explored in two papers [10,11]. Genetically similar halophilic Archaea occur in hypersaline ecosystems. Starting from this assumption, Kemp et al. [10] explore the hypothesis of migrating birds (such as the American Whyte Pelican) visiting the Great Salt Lake as mechanical carriers of halite crystals and their associated halophilic Archaea. Results confirm that halite- and bird feather-derived strains were affiliated with the genera Haloarcula and Halorubrum, which are commonly retrieved in hypersaline habitats worldwide. Gugliandolo and Maugeri [11] review the phylogenetic diversity of Archaea in sediments at shallow hydrothermal vents (Eolian Islands, Italy) characterized 
by highly prohibitive conditions (i.e., high temperatures, high concentrations of $\mathrm{CO}_{2}$ and $\mathrm{H}_{2} \mathrm{~S}$, and low $\mathrm{pH}$ ). The authors highlight the great influence exerted by geochemical parameters in shaping the archaeal community, which is mostly composed of hyperthermophilic Thermoprotei (among Crenarchaeota) and Euryarchaeota (Thermococci and Methanococci) at the highest temperature, while mesophilic Euryarchaeota increase with decreasing temperature values.

Searching for novel extremophiles is largely stimulating to the industry, as molecules from these microorganisms could be transformed into valuable biotechnological compounds. Streptomyces isolates from the Salar de Huasco (Chilean Altiplano of the Atacama Desert), an example of a polyextreme environment (in term of high salinity, aridity and solar radiation), show taxonomic divergences from the species with validly published names. More interestingly, isolates are able to produce novel secondary metabolites with antimicrobial activity and cytotoxicity, indicating the Salar de Huasco as a novel source of bacteria with pharmaceutical potential [12]. In their review paper, Finore et al. [13] fully describe the thermophilic Parageobacillus thermantarcticus strain M1, isolated from geothermal soil of Mount Melbourne (Antarctica) [14], as a potential microbial cell factory for the production of industrially important molecules with high bioeconomic value, such as thermoactive and thermostable enzymes (i.e., xylanase, beta-xylosidase, xylose/glucose isomerase, and a protease), to be applied in both industrial biocatalysis and certain bioprocesses (e.g., the bioconversion of agrowaste into xylo-oligomers and fermentable sugars), and exopolysaccharides (i.e., the xantan polymer EPS 1 and the mannan polysaccharide EPS 2) [15]. Nafis et al. [16] report on soil Actinobateria (including rare genera such as Nocardioides, Saccharomonospora, Actinomadura, and Prauserella) from extreme sites in Morocco as a promising microbial resource for optimizing green and sustainable agriculture in Morocco, due to the exhibition of distinctive plant growth-promoting activities (indole-3-acetic acid and siderophore production, $\mathrm{P}$ and $\mathrm{K}$ solubilization, and N-fixation). According to Barone et al. [17], Red Sea deep-hypersaline anoxic basins (DHABs) are among the most hostile environments on our planet, where anoxia and sulfidic conditions are combined with high salinity and hydrostatic pressure and the absence of light. Among eukaryotic extremophiles, fungi from the DHABs show high biotechnological potentialities, with members in the genera Aspergillus and Penicillium that could represent a reservoir of enzymes (e.g., amylases, lipases, and esterases), antibiotics, and antitumoural drugs.

In conclusion, the SI considers different aspects of extremophilic life occurring in different extreme habitats, both natural and anthropogenic, on Earth. We hope readers may find interesting inputs for their research, as a lot of work needs to be performed to better elucidate adaptation mechanisms and deepen current knowledge on microbial diversity in extreme environments.

This Special Issue serves as a memorial to Dr. Luigi Michaud (1974-2014), who dramatically passed away in Antarctica, in recognition of his passion for and contribution to the microbiology of extreme environments (Figure 1). We would like to thank all the authors from around the world (Europe, Japan, China, Canada, Morocco, Chile, and USA) for their contributions to the SI. Most of them have been Luigi's friends and colleagues, also working with him in the laboratory and in the field. We also wish to thank the staff members at the MDPI editorial office, and in particular Ms. Wei Zhang, for their support. 


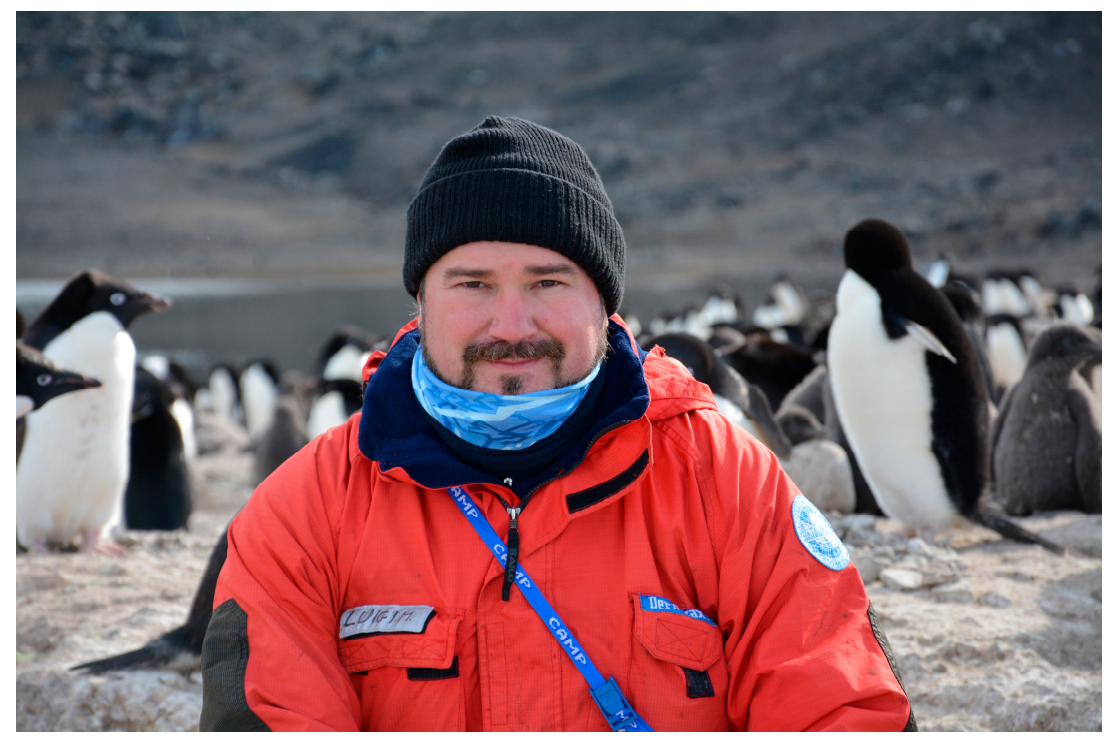

Figure 1. Luigi Michaud during his last Antarctic Expedition (Austral Summer 2013-2014). (c) PNRA.

Conflicts of Interest: The authors declare no conflict of interest.

\section{References}

1. MacElroy, R. Some comments on the evolution of extremophiles. Biosystems 1974, 6, 74-75. [CrossRef]

2. Sáenz, J.S.; Airo, A.; Schulze-Makuch, D.; Schloter, M.; Vestergaard, G. Functional Traits Co-Occurring with Mobile Genetic Elements in the Microbiome of the Atacama Desert. Diversity 2019, 11, 205. [CrossRef]

3. Chaya, A.; Kurosawa, N.; Kawamata, A.; Kosugi, M.; Imura, S. Community Structures of Bacteria, Archaea, and Eukaryotic Microbes in the Freshwater Glacier Lake Yukidori-Ike in Langhovde, East Antarctica. Diversity 2019, 11, 105. [CrossRef]

4. Rochera, C.; Camacho, A. Limnology and Aquatic Microbial Ecology of Byers Peninsula: A Main Freshwater Biodiversity Hotspot in Maritime Antarctica. Diversity 2019, 11, 201. [CrossRef]

5. Raffa, C.; Rizzo, C.; Strous, M.; Domenico, E.D.; Sanfilippo, M.; Michaud, L.; Giudice, A.L. Prokaryotic Dynamics in the Meromictic Coastal Lake Faro (Sicily, Italy). Diversity 2019, 11, 37. [CrossRef]

6. Fagorzi, C.; Del Duca, S.; Venturi, S.; Chiellini, C.; Bacci, G.; Fani, R.; Tassi, F. Bacterial Communities from Extreme Environments: Vulcano Island. Diversity 2019, 11, 140. [CrossRef]

7. Ma, J.; Luo, Z.; Chen, F.; Chen, R.; Zhu, Q.; Zhang, S. Impacts of Elevated $\mathrm{CO}_{2}$ Levels on the Soil Bacterial Community in a Natural $\mathrm{CO}_{2}$-Enhanced Oil Recovery Area. Diversity 2019, 11, 77. [CrossRef]

8. Chiellini, C.; Chioccioli, S.; Vassallo, A.; Mocali, S.; Miceli, E.; Fagorzi, C.; Bacci, G.; Coppini, E.; Fibbi, D.; Bianconi, G.; et al. Exploring the Bacterial Communities of Infernaccio Waterfalls: A Phenotypic and Molecular Characterization of Acinetobacter and Pseudomonas Strains Living in a Red Epilithic Biofilm. Diversity 2019, 11, 175. [CrossRef]

9. Ohlsson, J.I.; Osvatic, J.T.; Becraft, E.D.; Swingley, W.D. Microbial Community in Hyperalkaline Steel Slag-Fill Emulates Serpentinizing Springs. Diversity 2019, 11, 103. [CrossRef]

10. Kemp, B.L.; Tabish, E.M.; Wolford, A.J.; Jones, D.L.; Butler, J.K.; Baxter, B.K. The Biogeography of Great Salt Lake Halophilic Archaea: Testing the Hypothesis of Avian Mechanical Carriers. Diversity 2018, 10, 124. [CrossRef]

11. Gugliandolo, C.; Maugeri, T.L. Phylogenetic Diversity of Archaea in Shallow Hydrothermal Vents of Eolian Islands, Italy. Diversity 2019, 11, 156. [CrossRef]

12. Cortés-Albayay, C.; Silber, J.; Imhoff, J.F.; Asenjo, J.A.; Andrews, B.; Nouioui, I.; Dorador, C. The Polyextreme Ecosystem, Salar de Huasco at the Chilean Altiplano of the Atacama Desert Houses Diverse Streptomyces spp. with Promising Pharmaceutical Potentials. Diversity 2019, 11, 69. [CrossRef] 
13. Finore, I.; Lama, L.; Di Donato, P.; Romano, I.; Tramice, A.; Leone, L.; Nicolaus, B.; Poli, A. Parageobacillus thermantarcticus, an Antarctic Cell Factory: From Crop Residue Valorization by Green Chemistry to Astrobiology Studies. Diversity 2019, 11, 128. [CrossRef]

14. Nicolaus, B.; Lama, L.; Esposito, E.; Manca, M.C.; di Prisco, G.; Gambacorta, A. "Bacillus thermoantarcticus" sp. nov., from Mount Melbourne, Antarctica: A novel thermophilic species. Polar Biol. 1996, 16, 101-104.

15. Manca, M.C.; Lama, L.; Improta, R.; Esposito, E.; Gambacorta, A.; Nicolaus, B. Chemical Composition of Two Exopolysaccharides from Bacillus thermoantarcticus. Appl. Environ. Microbiol. 1996, 62, 3265-3269. [PubMed]

16. Nafis, A.; Raklami, A.; Bechtaoui, N.; El Khalloufi, F.; El Alaoui, A.; Glick, B.R.; Hafidi, M.; Kouisni, L.; Ouhdouch, Y.; Hassani, L. Actinobacteria from Extreme Niches in Morocco and Their Plant Growth-Promoting Potentials. Diversity 2019, 11, 139. [CrossRef]

17. Barone, G.; Varrella, S.; Tangherlini, M.; Rastelli, E.; Dell'Anno, A.; Danovaro, R.; Corinaldesi, C. Marine Fungi: Biotechnological Perspectives from Deep-Hypersaline Anoxic Basins. Diversity 2019, 11, 113. [CrossRef]

(C) 2019 by the authors. Licensee MDPI, Basel, Switzerland. This article is an open access article distributed under the terms and conditions of the Creative Commons Attribution (CC BY) license (http://creativecommons.org/licenses/by/4.0/). 